\title{
CANCER INCIDENCE IN CZECH BLACK COAL MINERS IN ASSOCIATION WITH COALWORKERS' PNEUMOCONIOSIS
}

\author{
HANA TOMASKOVA ${ }^{1,3}$, ZDENEK JIRAK $^{2}$, ANNA SPLICHALOVA ${ }^{1,3}$, and PAVEL URBAN ${ }^{4}$ \\ ${ }^{1}$ University of Ostrava, Ostrava Zabreh, Czech Republic \\ Faculty of Medicine, Department of Epidemiology and Public Health \\ ${ }^{2}$ University of Ostrava, Ostrava Zabreh, Czech Republic \\ Faculty of Medicine, Institute of Physiology and Pathophysiology \\ ${ }^{3}$ Institute of Public Health in Ostrava, Ostrava, Czech Republic \\ ${ }^{4}$ National Institute of Public Health, Prague, Czech Republic
}

\begin{abstract}
Objective: The aim of the study was comparison of cancer incidence risk of lungs, stomach, colon, bladder and kidneys from ex-miners of black coal mines and the general male population of the Czech Republic. Materials and methods: The analysis was conducted in two cohorts of ex-miners according to the presence of coalworkers' pneumoconiosis (CWP). The first cohort included the miners without CWP $(\mathrm{N}=6705)$, and the second cohort included the miners who were compensated for CWP $(\mathrm{N}=2158)$. Personal and occupational data was merged with the data in the National Population Register and the National Oncological Register for the period from 1992 to 2006. Cancer risk in miners in comparison to the general male population of the Czech Republic was evaluated by SIR (Standardized Incidence Ratio) and 95\% confidence interval (CI). Results: About twice as high risk of lung cancer was found in miners with CWP (SIR = 2.21; 95\% CI: 1.75-2.76). Lung cancer risk correlated with the severity of CWP (simple CWP SIR=1.96; 95\% CI: 1.48-2.56, progressive massive fibrosis SIR $=4.29 ; 95 \%$ CI: 2.09-7.87). No increased risk of lung cancer was found in ex-miners without CWP. The risk of malignant neoplasm at the other selected sites was comparable with the risk in the general male population of the Czech Republic. Conclusions: This study found increased lung cancer risk in coal miners with CWP, but not in those without CWP, comparing with the general population. These results served as the basis for the inclusion of lung cancer in association with CWP into a new Czech list of occupational diseases.
\end{abstract}

Key words:

Lung cancer, Coalworkers' pneumoconiosis, Black coal miners, Silica, Cancer incidence

\section{OBJECTIVES}

High dust concentration belongs to the most significant risk factors at work in coal mines.

Long-term inhalation of coal mining dust causes coalworkers' pneumoconiosis (CWP) and possibly other pathophysiological changes in the lung tissue. An important risk factor for pneumoconiosis in coal mines is the content of crystalline silica (quartz) in coal dust [1].

The content of crystalline silica can vary depending on the type of coal mine, location in the mine, and the type of job [1-4]. Epidemiologic evidence shows increased risk of lung cancer in relation to exposure to crystalline

This research was supported by a grant from the Czech Ministry of Health [NJ 8556].

Received: October 6, 2011. Accepted: January 17, 2012.

Address reprint request to H. Tomaskova, Institute of Public Health in Ostrava, Partyzanske nam. 7, 702 00 Ostrava, Czech Republic (e-mail: hana.tomaskova@zu.cz, hana.tomaskova@osu.cz). 
silica [5-7]. Based on the evidence, IARC classified crystalline silica as a carcinogen belonging to group I [8-9]. However, inconsistency of the epidemiologic evidence suggests that the carcinogenicity may be dependent on inherent characteristics of crystalline silica exposure or on external factors affecting its biological activity [8].

Studies on Polish [10], American [11] and British [12] coal miners did not find increased lung cancer risk. In more recent work, based on the same British data [13], a positive association between the risk of lung cancer and the exposure to crystalline silica was found.

Evidence from studies on German coal miners [14-16] is inconclusive. CWP in miners exposed to coal dust with high crystalline silica content was found to be associated with increased lung cancer mortality, supporting the risk attributed to the exposure to crystalline silica [16].

Studies of some other authors pointed to the increased risk of cancer of digestive system in miners exposed to dust of coal mines. Harrison et al. [17] found significantly more dyspeptic symptoms, histologically confirmed cases of acute and chronic gastritis and intestinal metaplasias in coal miners, in comparison to the general male population. Dutch authors [18] discovered significantly higher mortality from stomach cancer in miners in comparison to the general population; but mortality from lung cancer and cancer at the other sites was not significantly different from mortality in the general population [18-19]. Coggon et al. [20] found a positive (but not significant) association with the incidence of stomach cancer in coal miners and the length of exposure. Samanic et al. [21] provided a case-control study on the relationship between the risk of bladder cancer in different occupational groups in Spain. The risk in miners was not significantly higher and no association with the length of exposure was determined either.

The Czech study devoted to black coal miners [22] found higher, but not statistically significant lung cancer risk in miners with CWP. The study sample included only $10 \%$ of pneumoconiosis cases.
The aim of the presented study was to verify the results of the former study using a larger sample. The results are based on the comparison of cancer incidence risk in exminers of coal mines in association with and without CWP and the general male population of the Czech Republic.

\section{MATERIALS AND METHODS}

The analysis was conducted in two cohorts of black coal ex-miners (below only miners) of Ostrava-Karvina region (OKR). The first cohort (PN0) included the miners without CWP and the second cohort (PN1) included the miners who were compensated for CWP.

The miners in the cohort PN0 were selected from the original database of 7772 ex-miners of OKR. The database was created as part of the study that was conducted in the period from 2001 to 2003 [22]. The cohort PN0 consisted of 6705 surviving miners without CWP whose lung cancer - or another selected cancer - was not diagnosed before the start of the follow-up (1992). The miners were included in the cohort after finishing the work in underground conditions (1986-1999). The cohort PN1 consisted of 2158 ex-miners from OKR who were registered in the National Register of Occupational Diseases because of CWP diagnosis for which they were compensated in the period from 1992 to 2001.

The data about the date of birth, smoking habits (nonsmoker, smoker, ex-smoker), the length of exposure in a mine and category of CWP according to the list of occupational diseases valid in the Czech Republic in cohort PN1 was obtained.

Personal and occupational data of all miners in both cohorts was merged with the data from the National Population Register (date and diagnosis of death) and the Czech National Cancer Registry (date and diagnosis of disease) for the period from 1992 to 2006.

Cancer risk of miners from both cohorts in comparison to the general male population of the Czech Republic was evaluated by SIR (Standardized Incidence Ratio) 
and $95 \%$ confidence interval based on a Poisson assumption (CI) [23]. Indirect standardization to calculate expected incidence cases from malignant neoplasm at selected sites was used. Observed numbers were compared with these, stratified by 5-year age group and calendar year. The information about the incidence of cancer in men in the Czech Republic was obtained from the data of the National Health Information System.

All analyses were performed in statistical software STATA version 10 [24].

\section{RESULTS}

The average age of miners in the cohort PN0 at the onset of the follow-up was 44.1 years; they worked underground for 22.9 years on average. The average age of miners with CWP throughout the time when they were compensated for CWP was 47.8 years, and the average length of exposure during a mining profession was 20.4 years (Table 1). The data on the length of exposure was available only for $74 \%$ of the cohort.

The numbers of the newly reported cases with compensated CWP per year decreased during the follow-up period from 421 cases in 1992 to 99 cases in 2001. The miners in the cohort PN1 were divided into 4 categories according to the severity of CWP (Table 1). The biggest group included the miners with simple coal workers' pneumoconiosis (sCWP). In the second position, considering the frequency of occurrence, there were the miners who were diagnosed with an occupational disease "in relation to dynamic progression" initial form of CWP (iCWP). A complicated form of CWP (progressive massive fibrosis - PMF) and CWP in association with active tuberculosis (CWP\&TBC) were found only in about $10 \%$ of the cohort PN1. A statistically significant relationship between the severity of CWP and the length of exposure (a test for trend, $p<0.001$ ) and the age at the time of reporting (a test for trend, $p<0.001$ ) was found (Table 1). The shortest exposure was identified in the subgroup of miners with CWP\&TBC.

\section{Smoking habits}

The data on smoking habits was available in $99.8 \%$ of the miners in the cohort PN0 and in only $80 \%$ of the miners in the cohort PN1. Smoking habits of PN1 were similar to the general population. There was not found a significant difference ( $\chi^{2}$ test, $p=0.921$ ) in the distribution of nonsmokers in both samples of miners (33\%) and the general male population of the $\mathrm{CR}$.

A higher percentage of smokers (54\%) and a lower percentage of ex-smokers (13\%) were found in the cohort PN0,

Table 1. Description of the cohorts and CWP distribution

\begin{tabular}{lllccc}
\hline & & & \multicolumn{3}{c}{ Cohort } \\
\cline { 4 - 6 } Cohort & $\begin{array}{c}\text { Category } \\
\text { CWP }\end{array}$ & $\begin{array}{c}\text { Specification of the categories and ILO international } \\
\text { classification of radiographs of pneumoconiosis }\end{array}$ & $\mathrm{n}(\%)$ & $\begin{array}{c}\text { age } \\
\text { (years) }\end{array}$ & $\begin{array}{c}\text { exposure } \\
\text { (years) }\end{array}$ \\
\cline { 4 - 6 } & & & $6705(100)$ & $44.1(6.2)$ & $22.9(5.9)$ \\
PN0 & & $2158(100)$ & $47.8(12.6)$ & $20.4(7.8)$ \\
PN1 & & & $536(24.8)$ & $40.9(7.0)$ & $18.5(6.4)$ \\
& iCWP & Initial form of CWP (size of rounded opacities p2, q1, r1) & (SD) & M (SD) \\
\hline & SCWP & Simple CWP (size of rounded opacities p3, q2, r2, q3, r3) & $1400(64.9)$ & $49.4(12.8)$ & $21.5(8.1)$ \\
& PMF & Progressive massive fibrosis (A,B,C) & $95(4.4)$ & $61.4(13.5)$ & $23.8(9.1)$ \\
& CWP\&TBC & CWP in association with active tuberculosis & $127(5.9)$ & $49.6(14.0)$ & $18.2(8.2)$ \\
& & (all size of rounded opacities including A,B,C) & & & \\
\hline
\end{tabular}

CWP - coalworkers' pneumoconiosis, PN1 - miners with CWP, PN0 - miners without CWP, M - mean, SD - standard deviation. 
in comparison to both the cohort PN1 (44\% of smokers) and the general male population of the Czech Republic (41\% of smokers).

\section{Standardized Incidence Ratio}

In the follow-up period from 1992 to 2006, malignant neoplasm was diagnosed in $7 \%$ of the miners $(n=464)$ in the cohort PN0 and in $10 \%$ of the miners $(n=212)$ in the cohort PN1. Lung cancer was the most common malignant neoplasm in both cohorts. About 10\% $(n=681)$ of the miners in the cohort PN0 and 19\% $(\mathrm{n}=416)$ in the cohort PN1 died during the follow-up period. Figure 1 shows the distribution of person-years forming the population denominators for study incidence rates, by year of the follow-up from 1992 to 2006 inclusive. The total person-years of follow-up counted 85072 personyears in the cohort PN0 and 23345 person-years in the cohort PN1.

No significant cancer risk was found in the cohort PN0, similarly to the case of lung cancer, in comparison to the general male population of the Czech Republic (Table 2). A higher value of SIR, but not statistically significant, was found only for stomach cancer.

About twice as high risk of lung cancer was found in the cohort PN1 (regardless of the severity of CWP) in comparison to the male population of the Czech Republic (Table 2). A slight, but not statistically significant, increased

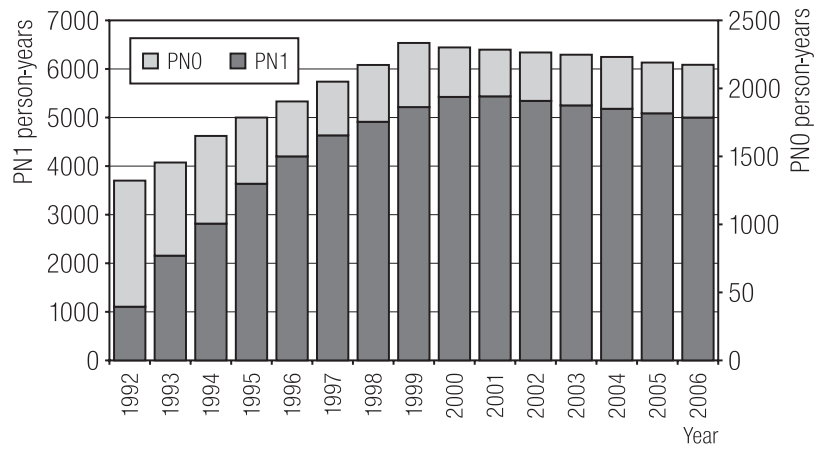

Fig. 1. Person-years in the cohort PN0 and PN1 by year of the follow-up from 1992 to 2006

risk of stomach and kidney cancer was found in the cohort PN1 (Table 2).

\section{Lung cancer}

In the cohort PN0, 93 miners with the average age of 57.8 years $(\mathrm{SD}=6.9)$ were diagnosed with lung cancer. In the cohort PN1, lung cancer was diagnosed in 74 miners with the average age of 64.1 years $(\mathrm{SD}=9.6)$. The percentage of smokers among the miners with and without lung cancer was not significantly different in the cohort PN1; however this finding was weakened by the fact that no information was available on the smoking habits in $51 \%$ of the miners with lung cancer.

The risk of lung cancer in the cohort PN1 was further analyzed according to the severity of CWP (Table 3) and the positive trend in SIR was found (a test for trend

Table 2. Incidence of malignant neoplasm and standardized incidence ratio with $95 \%$ confidence interval, at selected sites in the period 1992-2006

\begin{tabular}{lllcccc}
\hline \multicolumn{1}{c}{ Cohort } & \multicolumn{2}{c}{ Miners without CWP (cohort PN0) } & \multicolumn{2}{c}{ Miners with CWP (cohort PN1) } \\
\hline malignant neoplasm (ICD-10) & $\mathrm{n}(\%)$ & SIR & $95 \%$ CI & $\mathrm{n}(\%)$ & SIR & $95 \%$ CI \\
\hline Stomach (C16) & $20(4.3)$ & 1.15 & $0.72-1.74$ & $8(3.4)$ & 1.08 & $0.50-2.05$ \\
Colon (C18) & $35(7.5)$ & 0.88 & $0.62-1.20$ & $15(6.4)$ & 0.96 & $0.56-1.55$ \\
Lungs (C34) & $93(20.0)$ & 0.87 & $0.70-1.06$ & $74(31.8)$ & $2.21^{*}$ & $1.75-2.76$ \\
Kidney (C64) & $24(5.2)$ & 0.66 & $0.43-0.97$ & $12(5.2)$ & 1.07 & $0.58-1.82$ \\
Urinal bladder (C67) & $19(4.1)$ & 0.72 & $0.44-1.10$ & $10(4.3)$ & 0.95 & $0.48-1.69$ \\
\hline
\end{tabular}

CWP - coalworkers' pneumoconiosis, ICD - International Classification of Diseases, SIR - standardized incidence ratio, CI - confidence interval. $* \mathrm{p}<0.001$. 
Table 3. Incidence of lung cancer and standardized incidence ratio with 95\% confidence interval according to the severity of CWP in the cohort of miners with CWP in the period 1992-2006

\begin{tabular}{|c|c|c|c|c|c|c|}
\hline \multirow{2}{*}{ Category of CWP } & \multirow{2}{*}{ Total number } & \multicolumn{2}{|c|}{ Lung cancer (n) } & \multirow{2}{*}{ SIR } & \multirow{2}{*}{$95 \% \mathrm{CI}$} & \multirow{2}{*}{ p-value } \\
\hline & & observed & expected & & & \\
\hline iCWP & 536 & 4 & 3.7 & 1.08 & $0.34-2.61$ & 0.876 \\
\hline sCWP & 1400 & 51 & 26.0 & 1.96 & $1.48-2.56$ & $<0.001$ \\
\hline PMF & 95 & 9 & 2.1 & 4.29 & $2.09-7.87$ & $<0.001$ \\
\hline CWP\&TBC & 127 & 10 & 1.7 & 5.88 & $2.99-10.49$ & $<0.001$ \\
\hline
\end{tabular}

CWP - coalworkers' pneumoconiosis, iCWP - initial form of CWP, sCWP - simple CWP,

PMF - progressive massive fibrosis, CWP\&TBC - CWP in association with active tuberculosis, SIR - standardized incidence ratio,

$\mathrm{CI}$ - confidence interval.

in SIR, < 0.001). The risk of lung cancer in the miners with iCWP was comparable to that of the general male population of the Czech Republic. The risk was significantly higher in other categories, mainly in PMF and in CWP\&TBC.

\section{DISCUSSION}

This study found increased lung cancer risk in coal miners with CWP, but not without CWP, comparing with the general population.

The main criterion for the classification of miners into the cohorts PN0 or PN1 was the absence or presence of these persons in the National Register of Occupational Diseases because of CWP till the year 2001.

The cohort PN0 was nested within the data from the previous study [22], whose sub-criteria were working underground for at least 8 years or achieved maximum permissible exposure (MPE) [25], in order to get a group with homogenous exposure. MPE was expressed as a cumulative dose of respirable dust fraction and respirable crystalline silica fraction. The time of reaching $100 \%$ of MPE is connected with the probability that at the most $5 \%$ of miners are diagnosed with the initial form of pneumoconiosis (the finding of small opacities $p, q, r$ starting with the frequency of $1 / 1$ according to ILO [26]). The system of preventive replacement of miners from the work in the underground environment after reaching $100 \%$ of MPE had been gradually applied in the mines of the Czech Republic since 1986 and it came fully into force in 1990. Implementation of this preventive measure and also the reduction of mining in the Ostrava coal region resulted in the decrease of CWP cases during the follow-up period.

In the cohort PN1, apart from the main criterion, the data on the length of exposure was available, but not the individual dust exposure data in the miners. The National Register of Occupational Diseases did not contain this data and a retrospective search was not possible.

The severity of CWP in the miners of the cohort PN1 correlated with age and the length of exposure, with the exception of persons with CWP\&TBC, in whom the presence of active TBC was the main criterion for the acknowledgement of the occupational disease regardless of the severity of CWP. The lowest age and the shortest length of exposure were found in the miners with iCWP, in whom the occupational disease was acknowledged with regard to a short period of exposure up to the origin of initial radiographic changes in the pulmonary tissue and the assumed high risk of CWP progression in case of a further stay in a mine.

In addition to crystalline silica, which is an important risk factor of CWP [1], coal miners may be exposed also to other carcinogens that could influence the risk of lung cancer, such as radon, polycyclic aromatic hydrocarbons and fungi. These exposures might be ignored on the basis 
of information on negligible levels of such exposures from hygiene stations and also the results of the previous epidemiological study [27].

Smoking is considered the most important carcinogenic factor for the origin of lung cancer. It increases the risk of lung cancer from 3 to 10 -fold according to various authors, depending on the number of smoked cigarettes, the total length of smoking, age when taking up smoking and $\operatorname{sex}[6,22]$.

The missing data on smoking habits in $20 \%$ of the cohort PN1 was a certain weakness of our study. The percentage of missing data was caused by the incompleteness of the data in the National Register of Occupational Diseases and in the health records from the centers acknowledging occupational disease (CWP). On the other hand, the percentage of non-smokers in both cohorts of miners was not different from the proportion of non-smokers in the general population. The proportion of smokers in the cohort PN0 was higher in comparison to the general Czech male population [28] without having an influence on the risk of lung cancer in this cohort. We suggest that the incompleteness of the data about smoking habits in the cohort PN1 did not influence the results of our study. The main hypothesis of the study was that CWP is associated with lung cancer risk.

In line with our expectations, we did not confirm increased risk of lung cancer in the miners of the cohort PN0 and in the group of miners with the initial CWP form. The finding that the increased risk of lung cancer was confirmed only in the miners with simple to severe form of CWP suggests that the exposure to black coal dust containing crystalline silica does not increase the risk of lung cancer, however in association with CWP it becomes a significant risk factor of lung cancer.

The highest lung cancer risk was found in a sub-group of miners with CWP in association with active tuberculosis. Tuberculosis itself is considered a risk factor of lung cancer [29] and may be, apart from the life style, one of the highest lung cancer risk factors in the group of miners with CWP.

We suppose, on the basis of our results, that severe forms of CWP, similarly to silicosis, represent the increased risk of lung cancer in both smokers and non-smokers $[6,7,16]$. During chronic inflammation process, a great number of biologically active substances with genotoxic and proliferation stimulating effect are released, such as oxygen or nitrogen radicals, cyclooxygenases, cytokins, chemokins, and growth factors which can take part in the development of tumorous proliferation [30-32]. The finding of increased lung cancer risk in the miners with a severe CWP form points to a common mechanism of changes being in progress in the pulmonary tissue of the persons with silicosis and pneumoconiosis, which can in the end lead in some individuals to a tumorous proliferation.

Like other authors $[13,18,20]$, we also found increased risk (but not statistically significant) of stomach cancer in the cohorts of miners with CWP and without CWP as well. In the cohort PN0 we found a lower risk of malignant neoplasm at selected sites, with exception of stomach cancer, than in the general male population of the Czech Republic. This finding we attribute to "healthy worker effect," similarly to other authors $[11,13]$ who found this effect mainly at the beginning of the follow-up of the miners' cohort.

We did not find an increased risk of bladder cancer in the cohort PN1, conversely to the Samanic study [21]. The risk of malignant neoplasm at the other sites was identical to the risk of cancer in the general male population of the Czech Republic, similarly as in the Swaen study [18].

\section{CONCLUSION}

In the cohort of black coal miners with CWP, significantly higher lung cancer risk was found comparing with the general male population of the Czech Republic. Lung cancer risk increased along with the severity of coalworkers' pneumoconiosis. 
In the cohort of the miners without CWP, the risk of lung cancer was comparable with the male Czech population data. The risk of malignant neoplasm at the other selected sites (stomach, kidney, bladder and colon) in the miners was comparable with the general male population.

The presented study results served as the basis for inclusion of lung cancer in association with CWP into a new Czech list of occupational diseases.

\section{REFERENCES}

1. Rossiter CE. Relation between content and composition of coalworkers' lungs and radiological appearances. $\mathrm{Br} \mathrm{J}$ Ind Med 1972;29(1):31-44.

2. Einbrodt HJ. Quantitative and qualitative studies on dust retention in the human lung. Beitr Silikoseforsch 1965;87:1-105.

3. Fisher ER, Watkins G, Lam NV, Tsuda H, Hermann C, Johal J, et al. Objective pathological diagnosis of coal worker's pneumoconiosis. JAMA 1981;245(18):1829-34

4. Jirak Z. Epidemiology of silicosis and coal-workers' pneumoconiosis. In: Proceedings Eighth Interantional Conference on Occupational Lung Diseases; 1992 Sep 14-17, Prague, Czechoslovakia. Prague: ILO; 1992. p. 40-77.

5. Steenland K, Mannetje A, Boffetta P, Stayner L, Attfield M, Chen J, et al. Pooled exposure-response analyses and risk assessment for lung cancer in 10 cohorts of silica-exposed workers: an IARC multicentre study. Cancer Causes Control 2001;12(9):773-84.

6. Kurihara N, Wada O. Silicosis and Smoking Strongly Increase Lung Cancer Risk in Silica-Exposed Workers. Ind Health 2004, 42:303-314.

7. Pelucci C, Pira E, Piolatto G, Coggiola M, Carta P, La Vecchia C. Occupational silica exposure and lung cancer risk: a review of epidemiological studies 1996-2005. Ann Oncol 2006;17(7):1039-50.

8. IARC. Monographs on the evaluation of carcinogenic risks to humans. Vol. 68. Silica, some silicates, coal dust and para-aramid fibrils. Lyon: IARC; 1997.
9. Straif K, Benbrahim-Tallaa L, Baan R, Grosse Y, Secre$\tan$ B, El Ghissassi F, et al. WHO International Agency for Research on Cancer Monograph Working Group. A review of human carcinogens-part $C$ : metals, arsenic, dusts, and fibres. Lancet Oncol 2009;10(5):453-4.

10. Starzyński Z, Marek K, Kujawska A, Szymczak W. Mortality among coal miners with pneumoconiosis in Poland. Int J Occup Med Environ Health 1996;9(4):279-89.

11. Attfield MD, Kuempel ED. Mortality among U.S. underground coal miners: a 23-year follow-up. Am J Ind Med 2008;4:231-45.

12. Miller BG, Jacobsen M. Dust exposure, pneumoconiosis, and mortality of coalminers. Br J Ind Med 1985;42(11):723-33.

13. Miller BG, Maccalman L. Cause-specific mortality in British coal workers and exposure to respirable dust and quartz. Environ Med 2010;67(4):270-6.

14. Morfeld P, Lampert K, Ziegler H, Stegmaier C, Dhlom G, Piekarski C. Coal mine dust exposure and cancer mortality in German coal miners. Appl Occup Environ Hyg 1997;12:909-14.

15. Latza U, Degens P, Baur X. Lung cancer risk associated with quartz and coal mine dust exposure. Arbeitsmed Sozialmed Umweltmed 2000, 35:424-438 [in German].

16. Morfeld P, Lampert K, Emmerich M, Reischig HL, Klinker HG, Bauer $\mathrm{H}$, et al. Lung cancer risks in coal mining: $a$ mortality study in relation to quartz dust exposure and pneumoconiosis. Arbeitsmed Sozialmed Umweltmed 2003;38(3):44 [in German].

17. Harrison JD, Morris DL, Hardcastle JD. Screening for gastric carcinoma in coal miners. Gut 1993;34(4):494-8.

18. Swaen GM, Meijers JM, Slangen JJ. Risk of gastric cancer in pneumoconiotic coal miners and the effect of respiratory impairment. Occup Environ Med 1995;52(9):606-10.

19. Meijers JM, Swaen GM, Slangen JJ, van Vliet K, Sturmans F. Long-term mortality in miners with coal workers' pneumoconiosis in The Netherlands: a pilot study. Am J Ind Med 1991;19(1):43-50.

20. Coggon D, Barker DJ, Cole RB. Stomach cancer and work in dusty industries. Br J Ind Med 1990;47(5):298-301. 
21. Samanic CM, Kogevinas M, Silverman DT, Tardón A, Serra C Malats N, et al. Occupation and bladder cancer in a hospital-based case-control study in Spain. Occup Environ Med 2008;65(5):347-53.

22. Tomaskova H, Jirak Z, Menzlova M, Beska F, Zavadilova V, Cimova K, et al. Dusts Containing Quartz and Carcinogenicity Risk in Mines: Epidemiological Study. In: Donnelly KC, Cizmas LH, editors. Environmental Health in Central and Eastern Europe. Dordrecht: Springer; 2006. p. 181-7.

23. Checkoway H, Pearce N, Kriebel D. Research Methods in Occupational Epidemiology. New York: Oxford University Press; 2004.

24. Stata: Stata Statistical Software: Release 10. College Station (TX): Stata Corporation; 2007.

25. Jirák Z, Škoda V, Holuša R, Karpíšek L, Jiráková D, Jiráková $\mathrm{H}$, et al. The maximum allowable concentration of respirable fraction of the dust from mining of the Ostrava-Karviná coal miners determined on the basis analysis the lungs deceased miners. Pracov Lék 1995;47(6):252-61 [in Czech].

26. ILO. Guidelines for the use of ILO international classification of radiographs of pneumoconioses. Geneva: ILO; 1980.

27. Dobiáš L, Gajdošová D, Šrám RJ, Janča L, Roda Š. Risk associated with inhalation of fungal metabolites. In Procceding of the Internat. In: Waters MD, editor. Conference on Genetic Toxicology of Complex Mixtures; 1989 July 4-7; Washington, D.C., USA. New York : Plenum Press; 1990.

28. Institute of Health Information and Statistics of the Czech Republic. Sample survey of the health status of the Czech population 1999. Prague: UZIS; 2001 [cited 2009 November 5]. Available from: http://www.uzis.cz/download. php?ctg $=10 \&$ mnu_id $=5300 \& \operatorname{lng}=$ en.

29. Liang HY, Li XL, Yu XS, Guan P, Yin ZH, He QC, et al. Facts and fiction of the relationship between preexisting tuberculosis and lung cancer risk: a systematic review. Int J Cancer 2009;125(12):2936-44.

30. Cocco P, Dosemeci M, Rice C. Lung cancer among silicaexposed workers: the quest for truth between chance and necessity. Med Lav 2007;98(1):3-17.

31. Hamilton RF Jr, Thakur SA, Holian A. Silica binding and toxicity in alveolar macrophages. Free Radic Biol Med 2008;44(7):1246-58.

32. O'Byrne KJ, Dalgleisch AG. Chronic immune activation and inflammation as the cause of malignancy. $\mathrm{Br} \mathrm{J}$ Cancer 2001;85:473-83.

This work is available in Open Access model and licensed under a Creative Commons Attribution-NonCommercial 3.0 Poland License - http://creativecommons.org/ licenses/by-nc/3.0/pl/deed.en. 